\section{Hemorragia adrenal bilateral en paciente recuperado de neumonía COVID-19 Grave. Caso Radiológico}

\author{
ROBERTO MIRANDA ${ }^{1}$, RODRIGO RAURICH ${ }^{1}$, RICARDO ARIS $^{1}$, \\ DIEGO RAMÍREZ ${ }^{1}$, CHRISTIAN HIDALGO ${ }^{1}$
}

\section{Bilateral adrenal hemorrhage after severe COVID-19 infection. Report of one case}

We report a 47-year-old male with a severe disease caused by COVID-19, who required mechanical ventilation for 18 ays. During the hospital stay he received dexamethasone and anticoagulation with heparin. After discharge a new chest CT scan showed homogeneous hypo vascular enlargement of both adrenal glands, not present in the initial imaging studies. It was interpreted as a subacute bilateral adrenal hemorrhage. The patient remained stable and without any complaint.

(Rev Med Chile 2021; 149: 1081-1084)

Key words: Adrenal hemorrhage; COVID-19; Tomography Scanners, X-Ray Computed.
Servicio de Radiología, Clínica Red Salud Providencia. Santiago, Chile.

Este trabajo no recibió financiamiento.

Los autores declaran no tener conflictos de interés.

Recibido el 9 de septiembre de 2020, aceptado el 4 de agosto de 2021.

Correspondencia a:

Dr. Roberto Miranda

Servicio de Radiología, Clínica

Red Salud Providencia. Santiago,

Chile.

rmradiologia@gmail.com
$\mathrm{E}$ $\mathrm{n}$ los largos meses de pandemia de este año 2020, el personal dedicado a la salud ha tenido que aprender día a día nuevos hallazgos o manifestaciones causadas por esta nueva partícula viral conocida como SARS-CoV-2. Los radiólogos hemos visto las variadas manifestaciones en las imágenes no solo del compromiso pulmonar, sino que también del sistema nervioso central, abdominal y músculo esquelético entre otros.

En este artículo se presenta un hallazgo inusual en un paciente confirmado con COVID-19, esto correspondió a hemorragia suprarrenal. Esta es una patología poco frecuente, pero importante de reconocer en pacientes graves como los afectados por COVID-19. Puede desencadenar una insuficiencia adrenal aguda, que agrave el diagnóstico inicial o incluso causar la muerte.

\section{Caso clínico}

Paciente varón de 47 años, previamente sano y sin antecedentes mórbidos, conductor del transantiago. Su cuadro se inicia a fines de mayo de
2020. El día 30 de mayo le confirman PCR específica positiva para SARS-CoV-2. Evoluciona con mayor compromiso del estado general, mialgias, cefalea, fiebre hasta $38^{\circ} \mathrm{C}$ y disnea progresiva. Se realiza tomografía computada de tórax (TC) que muestra extensas opacidades en vidrio esmerilado bilateral y moderada disminución del volumen pulmonar (Figura 1a). Se resalta en esa TC, el aspecto normal de ambas suprarrenales (Figura 1b). Es internado el día 2 de junio y ese mismo día ingresado a la unidad de cuidados intensivos con una $\mathrm{FiO}_{2}$ de $92 \%$. Esa noche es intubado y conectado a ventilación mecánica. El día 12 de junio se realiza traqueostomía permaneciendo así por otros 9 días. Recibió durante su hospitalización, tratamiento con dexametasona y heparina endovenosa. Evolucionó favorablemente, siendo dado de alta el 12 de julio.

Se mantiene en control ambulatorio con broncopulmonar con parámetros inflamatorios en regresión. El Dímero D bajó de $2.874 \mathrm{ng} / \mathrm{ml}$ el 5 de junio a $591 \mathrm{ng} / \mathrm{ml} \mathrm{el} 20$ de agosto. La ferritina de $834 \mathrm{ng} / \mathrm{ml}$ a $154 \mathrm{ng} / \mathrm{ml}$. La VHS de $60 \mathrm{~mm} / \mathrm{h}$ bajó a $18 \mathrm{~mm} / \mathrm{h}$, los leucocitos de 13.232 a 8.400 , 


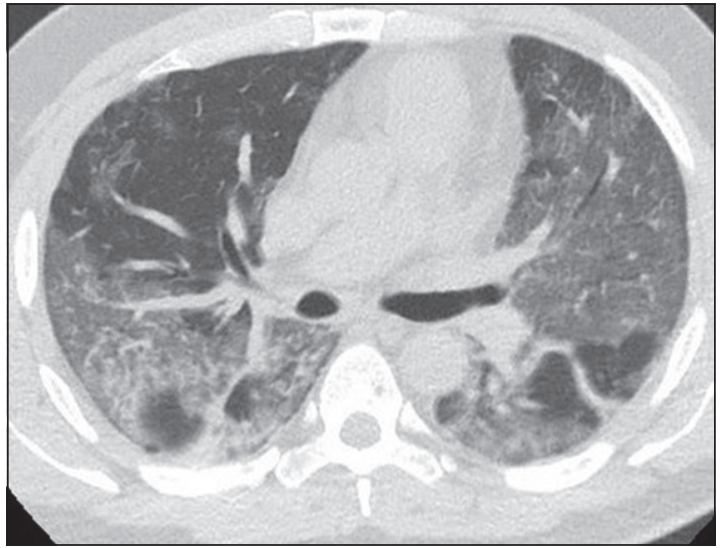

Figura 1a. Imagen axial de TC, de ingreso, muestra extensas opacidades pulmonares en vidrio esmerilado bilaterales, de distribución periférica en contexto de PCR + para Coronavirus.

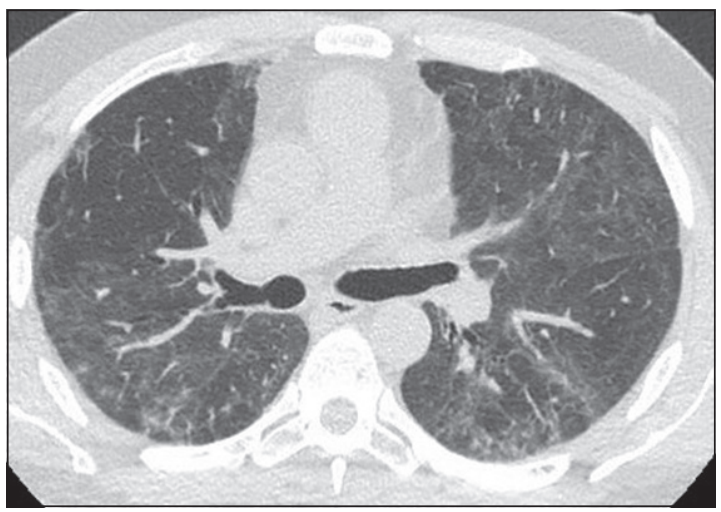

Figura 2. TC de control a los 2 meses de evolución, muestra significativa regresión del compromiso pulmonar en relación al primer examen.

la proteína C reactiva de $362 \mathrm{mg} / \mathrm{ml}$ bajó a $8 \mathrm{mg} /$ $\mathrm{ml}$. El paciente siguió con tratamiento esteroidal de mantención.

Por persistir una disnea a esfuerzos leves, se solicitó una TC de tórax. Las alteraciones pulmonares habían regresado significativamente, quedando engrosamientos intersticiales residuales y algunas opacidades en vidrio esmerilado (Figura 2). Sin embargo, como hallazgo incidental presentó crecimiento suprarrenal bilateral homogéneo, hipovascular, no presente en el examen inicial ( $\mathrm{Fi}-$ gura 3a, 3b y 4 ). Se planteó hemorragia suprarrenal bilateral subaguda (HSB). El paciente se mantuvo estable, con licencia médica, sin molestias en reposo hasta el envío de este artículo.

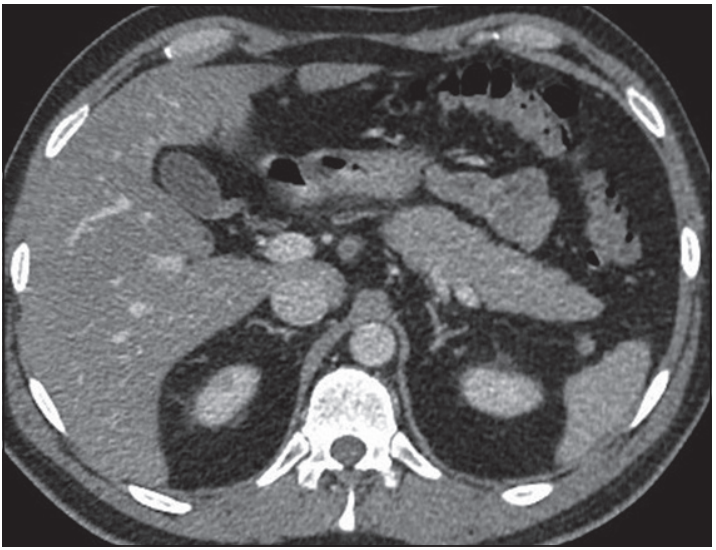

Figura 1b. Imagen axial del TC inicial a nivel del polo superior de los riñones, muestra ambas glándulas suprarrenales de aspecto y tamaño normales.

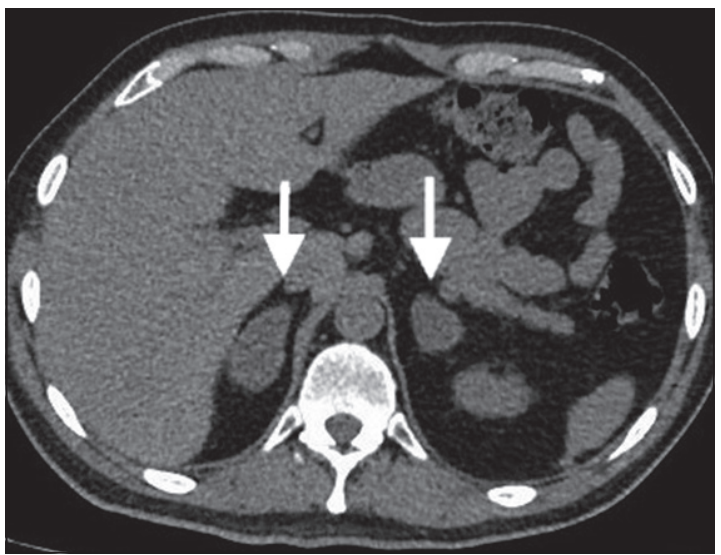

Figura 3a. TC de control a los 2 meses de evolución a nivel suprarrenal con aumento de tamaño de ambas glándulas (flechas), homogéneo, bien delimitado.

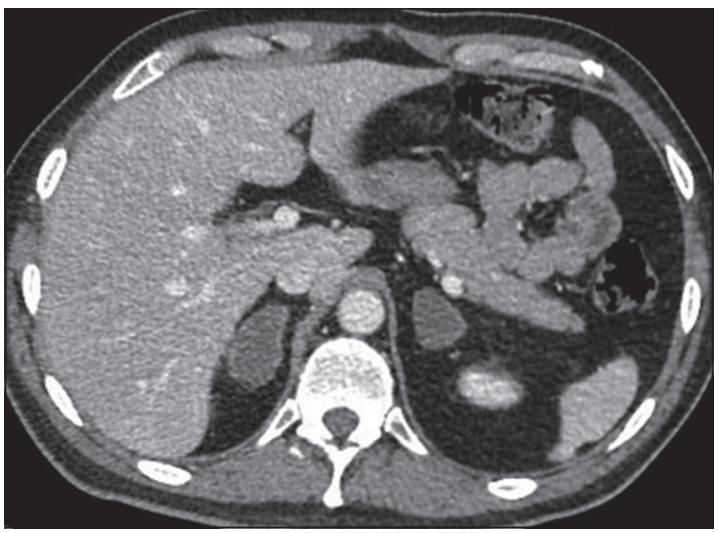

Figura 3b. TC con contraste al mismo nivel de figura $3 a$, no muestran realce significativo. 


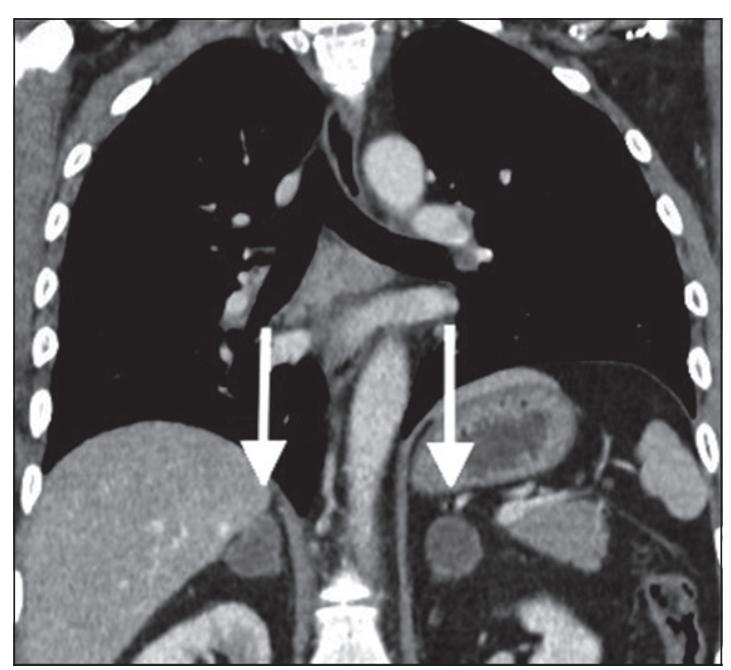

Figura 4. TC con contraste en plano coronal, muestra ambas regiones suprarrenales de manera comparativa, con las glándulas aumentadas de tamaño (flechas).

Para el reporte de este caso clínico, contamos con el debido consentimiento oportuno del paciente para publicar de forma anónima estos hallazgos y para la realización de los exámenes radiológicos presentados.

\section{Discusión}

La pandemia por coronavirus declarada por la OMS el 11 de marzo de $2020^{1}$, ha afectado fuertemente a Chile. Según cifras del Minsal al 31 de agosto de $2020^{2,3}$, Chile está entre los 10 países con más contagios demostrados en el mundo y $5^{\circ}$ en Latinoamérica, con más de 410.000 contagiados. Aunque la recuperación es alta por sobre $90 \%$ y la letalidad es baja de $2,7 \%$, ha obligado a ampliar significativamente la capacidad de los servicios de salud, principalmente de camas críticas y disponibilidad de respiradores mecánicos. En el peak de la pandemia en Chile, hubo casi 7.000 contagios por día y una ocupación mayor a 2.800 ventiladores mecánicos, con 437 pacientes en estado crítico $^{2,3}$.

Las manifestaciones abdominales más frecuentemente detectadas con tomografía computada en pacientes con COVID-19 son gastrointestinales y colestasia ${ }^{4}$. La hemorragia suprarrenal aguda no traumática, es una patología poco frecuente y el compromiso bilateral agudo menos frecuente aún, con una incidencia de $0,14-1,8 \%$ en estudios de autopsias ${ }^{5}$. Puede llevar a una insuficiencia adrenal aguda con consecuencias graves si no se administra precozmente tratamiento glucocorticoides, con una mortalidad global de $15 \%$ que puede llegar hasta $50 \%$ en pacientes con sepsis ${ }^{6}$. La causa no es del todo conocida pero se cree que condiciones anatómicas como la gran irrigación arterial con un pobre drenaje venoso asociado a mecanismos de espasmo venoso o trombosis, pueden contribuir a una hiperplasia adrenal e infartos hemorrágicos ${ }^{7,8}$.

Existen varios factores clásicos predisponentes como sepsis, coagulopatías y enfermedades procoagulantes, tratamiento anticoagulante, uso de glucocorticoides, embarazo, tumores adrenales ${ }^{6}$, exceso de ACTH asociado a stress, como ocurre en paciente crítico, que puede aumentar el flujo sanguíneo adrenal. Los pacientes internados en las UPC, principalmente en estos últimos 5 meses casi exclusivamente por COVID-19, cumplen uno o más de estos factores de riesgo. Son pacientes intubados con grave insuficiencia respiratoria aguda, que desarrollan coagulopatía por la reacción inflamatoria producida por el coronavirus y muchos de ellos con tratamiento anticoagulante, como en nuestro caso. Estos son sin duda, pacientes candidatos a desarrollar una hemorragia suprarrenal. Dada su crítica condición clínica y el tratamiento esteroidal asociado, la sintomatología de una insuficiencia suprarrenal es poco evidente u oculta ${ }^{5,8}$.

Los métodos de diagnóstico por imagen que demuestran esta patología son el ultrasonido, la resonancia magnética y principalmente la TC. Por el estado en que se encuentran estos pacientes y además por la falta de una clínica clara, se hace difícil pedir estos exámenes. Por su gravedad no pueden ser trasladados a los servicios de imágenes.

La TC es una de las principales técnicas de diagnóstico por imágenes de la hemorragia suprarrenal y el aspecto dependerá del tiempo de evolución:

En fase aguda generalmente hasta el $7^{\circ}$ día, la glándula aparece aumentada de tamaño y espontaneamente densa, con poco realce posterior al uso de contraste endovenoso. El tejido adiposo retroperitoneal puede estar aumentado de densidad alrededor de la glándula.

- En fase subaguda se hace hipodensa, con poco refuerzo con el contraste y de contornos mejor delimitados.

- En fase crónica después de 7 semanas, la glándula disminuye de tamaño y pueden aparecer calcificaciones densas ${ }^{9,10}$. 
Nuestro caso, fue controlado con TC de tórax a los 2 meses dada la grave neumonia que presentó inicialmente y la leve disnea que presentaba al momento del examen, buscando principalmente la presencia de secuelas pulmonares. Sin duda que la HSB fue un importante hallazgo. No sabemos la real prevalencia que pueda tener sobretodo por el gran número de pacientes críticos que se han visto tanto en Chile como en el mundo. Al día de hoy, solo hemos encontrado un par de artículos de HSB en paciente COVID-19 que muestran esta asociación, que aunque al parecer no es causa efecto o por daño directo del SARS-CoV-2, pero ninguno de ellos muestra el estado previo de las glándulas. Los pacientes con COVID-19 en condición crítica y en tratamientos intensivos, deberían tener evaluación de la función adrenal antes del alta definitiva, principalmente por el alto número de pacientes en estado crítico que se han presentado con la pandemia.

COVID-19 es una enfermedad nueva ${ }^{11}$ y día a día nos muestra nuevas y diferentes manifestaciones o complicaciones. Los reportes acerca de asociación con daño adrenal por SARS-CoV-2 son escasos ${ }^{5,6}$.

\section{Conclusión}

Se presenta un caso inhabitual de hemorragia suprarrenal bilateral no traumática, en un paciente tratado por COVID-19 grave. Nuestro artículo demuestra con TC el cambio de aspecto de las glándulas suprarrenales en la evolución de nuestro paciente. Aunque el hallazgo fue incidental después del alta hospitalaria, es un hallazgo a considerar dentro de las complicaciones poco frecuentes. Según la evolución clínica se puede hacer control de la función adrenal y considerar la posibilidad de realizar una tomografía computada. La real frecuencia de esta entidad no está demostrada, más aún en una enfermedad nueva, donde se desconocen muchos de sus aspectos clínicos.

\section{Referencias}

1. World health organization. Alocución Del Director General Dr. Tedros Adhanom Sobre COVID-19. 2020, Marzo 11 [03/09/2020].

2. MINSAL. Informe Epidemiológico No 47. Agosto 31,2020 . https://www.minsal.cl/wp-content/ uploads/2020/09/Informe-Epidemiológico-47.pdf [03/09/2020].

3. Gobierno de Chile. Reporte Diario. Septiembre 01, 2020. https://cdn.digital.gob.cl/public_files/Campañas/ Corona- Virus/Reportes/01.09.2020_Reporte_Covid19. pdf [03/09/2020].

4. Bhayana R, Som A, Li MD, Carey DE, Anderson MA, Blake MA, et al. Abdominal Imaging Findings in COVID-19: Preliminary Observations. Radiology May 2020. Published Online. https://doi.org/10.1148/ radiol.2020201908.

5. Álvarez-Troncoso J, Zapatero Larrauri M, Montero Vega MD, Gil Vallano R, Palmier Peláez E, Martín Rojas-Marcos P, et al. Case Report: COVID-19 With Bilateral Adrenal Hemorrhage. Am. J Trop Med Hyg. 2020; 103 (3): 1156-7.

6. Frankel M, Feldman I, Levine M, Frank Y, Bogot NR, Benjaminov $\mathrm{O}$, et al. Bilateral Adrenal Hemorrhage in Coronavirus Disease 2019 Patient: A Case Report. J Clin Endocrinol Metab. 2020; 105 (12): dgaa487.

7. Jordan E, Poder L, Courtier J, Sai V, Jung A, Coakley FV. Imaging of nontraumatic adrenal hemorrhage. AJR Am J Roentgenol 2012; 199: W91-8.

8. Bellastella G, Maiorino MI, Esposito K. Endocrine complications of COVID-19: what happens to the thyroid and adrenal glands? J Endocrinol Invest 2020; 43: 1169 70.

9. Alves Pereira FD, Hickson ML, Wilson PAJ. Case 268: Bilateral Adrenal Hemorrhage in the Contest of Sepsis. Radiology 2019; 292: 503-6.

10. García Espinosa J, Romera Romera N, Salmerón Ruiz M, Medina Benítez A. Hallazgos Radiológicos en la Hemorragia Suprarrenal Traumática y Espontánea ¿Qué nos Aportan las Diferentes Técnicas de Imagen? SERAM 2014, https://dx.doi.org/10.1594/seram2014/S-0392.

11. Arteaga Herrera O. COVID-19. Rev Med Chile 2020; 148: 279-80. 